\title{
HUMANIDADES DIGITAIS E DIÁSPORA AFRICANA: QUESTÕES ÉTICAS E METODOLÓGICAS NA ELABORAÇÃO DE UMA BASE DE DADOS SOBRE A POPULAÇÃO ESCRAVIZADA DE MARIANA (SÉCULO XVIII $)^{1}$
}

Digital humanities and the African diaspora: ethical and methodological challenges in designing a database on Mariana's enslaved population (Eighteenth century)

Las humanidades digitales y diáspora africana: cuestiones éticas y metodológicas en el diseño de una base de datos sobre la población esclavizada de Mariana (siglo XVIII)

ALDAIR RODRIGUES ${ }^{*}$

DOI: http://dx.doi.org/10.1590/S2178-14942020000100005

\footnotetext{
' Universidade Estadual de Campinas (Unicamp), Campinas (SP), Brasil.

* Professor do Departamento de História da UNICAMP e vice-diretor do Arquivo Edgard Leuenroth (aldair16@unicamp.br). ORCID ID: https://orcid.org/0000-0002-5360-1120.

Artigo recebido em 31 de julho de 2019 e aprovado para publicação em 3 de dezembro de 2019.
} 
HUMANIDADES DIGITAIS E DIÁSPORA AFRICANA: QUESTÕES ÉTICAS E METODOLÓGICAS NA ELABORAÇÃO DE UMA BASE DE DADOS SOBRE A POPULAÇÃO ESCRAVIZADA DE MARIANA (SÉCULO XVIII)

\title{
RESUMO
}

Adotando como estudo de caso a elaboração de uma base de dados sobre a população escravizada que viveu na região de Mariana (Minas Gerais) no século XVIII, este artigo reflete sobre os desafios éticos e metodológicos subjacentes às abordagens digitais sobre a diáspora africana. A análise enfoca as especificidades e os desafios envolvidos no processo de transposição de informações históricas produzidas no contexto da escravidão para sistemas digitais. Quais são as potencialidades e os riscos dessa tarefa em um país social e étnico-racialmente desigual como o Brasil?

PALAVRAS-CHAVE: Diáspora africana; Humanidades digitais; História digital; Base de dados; Ensino de história.

\begin{abstract}
This article addresses ethical and methodological challenges underlying the digital approaches to the African diaspora. It takes the process of building a database about the enslaved population that lived in the region of Mariana (Minas Gerais) during the Eighteenth century as a case study. It analyzes the consequences of the insertion of historical information produced in a context marked by the asymmetrical power relations legitimized by slave ideology into digital systems. What are the potentialities and risks of this task in a socially and racially unequal country like Brazil?
\end{abstract}

KEYWORDS: African diaspora; Digital humanities; Digital history; Database; Teaching history.

\section{RESUMEN}

Tomando como caso de estudio el desarrollo de una base de datos sobre la población esclavizada que vivió en la región de Mariana (Minas Gerais) en el siglo XVIII, este artículo reflexiona sobre los desafíos éticos y metodológicos que subyacen a los enfoques digitales de la diáspora africana. El análisis se centra en los detalles y desafíos involucrados en el proceso de transposición de información histórica producida en el contexto de la esclavitud a los sistemas digitales. ¿Cuáles son las potencialidades y los riesgos de esta tarea en un país social y étnicamente racialmente desigual como Brasil?

PALABRAS CLAVE: Diáspora africana; Humanidades digitales; Historia digital; Base de datos; Enseñanza de la historia. 


\section{INTRODUÇÃO}

dotando como estudo de caso a elaboração de uma base de dados sobre a população
escravizada que viveu na região de Mariana (Minas Gerais) no século XVIII, este artigo reflete sobre os desafios éticos e metodológicos subjacentes às abordagens digitais sobre a diáspora africana. São enfocados os aspectos relacionados com as origens das pessoas escravizadas e sua agência histórica.

0 texto encontra-se articulado a partir de dois eixos principais. No primeiro, oferecemos um panorama descritivo dos impactos das tecnologias digitais nos projetos que utilizam documentação produzida em contextos escravistas e, em seguida, expomos as principais características e objetivos da base de dados sobre as origens dos africanos e africanas que viveram na região de Mariana no século XVIII. No segundo eixo, desenvolvemos uma reflexão sobre as dimensões éticas e epistemológicas que nortearam a construção dessa base de dados. Ganham destaque nessa parte as discussões tocantes à inserção social do projeto e as consequências de o processo de criação dos registros estar baseado no protagonismo das pessoas escravizadas.

0 fio condutor do artigo são as implicações da transposição de informações históricas presentes em documentos produzidos em um contexto marcado pelas relações de poder escravistas para sistemas digitais. Quais são as potencialidades e os riscos dessa tarefa em um país social e étnico-racialmente desigual como o Brasil?

0 enfrentamento desses desafios agrega contribuições ao campo das humanidades digitais e da história digital, um de seus subcampos. Interessa compreender as transformações contemporâneas no processo de produção do conhecimento nas ciências humanas e historicizar os efeitos da aplicação da informática na operação historiográfica. Stricto sensu, o conceito de documento não sofre modificações em sua dimensão digital, porque, segundo Paes (2004: 26), "documento é o registro de uma informação, independente da natureza do suporte que a contém". Porém, acreditamos que as tecnologias digitais impactam os procedimentos envolvendo as buscas de informações em geral, as pesquisas em fontes primárias (digitalizadas), a coleta, a organização e a análise de evidências históricas, bem como as relações sociais que permeiam o trabalho do historiador (Lucchesi, 2014; Câmara e Benício, 2017).

0 projeto tomado aqui como estudo de caso dialoga com reflexões centradas em outras experiências que lidaram com a elaboração de recursos digitais, pois a área de estudos que compreende a vida dos africanos e seus descendentes no mundo atlântico foi uma das mais impactadas pela penetração das tecnologias digitais nas ciências humanas. Em parte, isso se 
HUMANIDADES DIGITAIS E DIÁSPORA AFRICANA: QUESTÕES ÉTICAS E METODOLÓGICAS NA ELABORAÇÃO DE UMA BASE DE DADOS SOBRE A POPULAÇÃO ESCRAVIZADA DE MARIANA (SÉCULO XVIII)

explica pela natureza seriável dos documentos produzidos pela contabilidade comercial do tráfico, pelas fontes cartoriais que registravam as transações envolvendo pessoas escravizadas e pelos registros paroquiais de batismo e óbito. De acordo com Daryle Williams (2018), as informações presentes naquelas tipologias, embora apresentassem algum grau de variabilidade quanto aos contextos dos quais foram extraídas, compunham uma grelha básica de variáveis separadas por vírgulas (quando não são preenchidas em tabelas impressas). Nos sistemas informáticos, elas tendem a ser facilmente replicadas em planilhas, colunas e células de softwares voltados para a recolha e o tratamento de grandes volumes de dados. Na apreciação do autor, essa é uma das principais características dos estudos sobre o tráfico na era digital.

Podemos afirmar que o grande precursor da produção de conhecimento em torno da aplicação da informática em metodologias quantitativas a respeito do tráfico transatlântico foi o projeto Voyages - Slave Trade Database. Conforme entrevista de David Eltis a Leonardo Marques (2019), o histórico de desenvolvimento do projeto confunde-se com a própria história da penetração da computação nas ciências humanas. Primeiro, por testemunhar o esforço coletivo para reunião dos dados seriados sobre o volume e os fluxos do tráfico que vinham sendo compilados por pesquisadores dispersos por várias universidades desde as décadas de 1960 e 1970. Seu primeiro resultado foi publicado em 1999 em CD-ROM (Eltis et al., 1999). Segundo, pela disponibilização dos dados online de maneira interativa, na medida em que a internet se popularizava. 0 projeto tornou acessível para um vasto público o levantamento mais completo que se conhece acerca dos números e das estatísticas do tráfico negreiro, com as origens e os destinos das embarcações e o volume de pessoas transportadas. Em seu website, é possível encontrar ainda uma série de artigos que orientam seus usuários sobre a dinâmica da base, as metodologias e as práticas adotadas em sua construção e uma série de recursos imagéticos que funcionam como ferramentas didático-pedagógicas. ${ }^{2}$

Nos últimos anos, notamos uma ampla diversificação das iniciativas relacionadas com o passado escravista das Américas que vão muito além das estatísticas do tráfico. Jorge Felipe (2016) [Sim, consta], um dos editores da rede de pesquisadores que alimenta o fórum $\mathrm{H}$-slavery no portal Humanities and Social Science Online, computou um total de 54 projetos (junto com seus respectivos links), que se encontram atualmente disponíveis na web ou em andamento (Flores, 2016). Notamos importantes avanços nas relações entre os projetos e a sociedade, mormente no que se refere à memória da experiência histórica das populações negras das Américas. Os repertórios disponibilizam imagens e fontes visuais; entrevistas e recursos audiovisuais; mapas; digitalização de fontes seriáveis e qualitativas; e bases de dados de diferentes alcances e em diferentes estágios de desenvolvimento. 
Parte dessas iniciativas elencadas por Flores (2016) engajou-se em um esforço para superar o peso excessivo das abordagens quantitativas que se expandiram na esteira do projeto Voyages - Slave Trade Database. Alternativamente, elas tendem a privilegiar a reconstituição de biografias e memórias vivenciadas em contextos escravistas do Atlântico. De alguma forma, estariam em sintonia com a "virada biográfica" (biographical turn) que marcou a historiografia do tráfico e da escravidão a partir dos anos 2000, conforme análise de Joseph Miller (2013).

0 exemplo mais contundente do impacto da "virada biográfica" é o projeto interdisciplinar Enslaved: Peoples of the Historic Slave Trade, liderado por Walter Hawthorne no Centro de Humanidades Digitais e Ciências Sociais da Michigan State University. Seu foco é a compilação e a disponibilização na web de uma série de bancos de dados que possibilitem a recuperação de informações sobre as biografias de pessoas escravizadas. ${ }^{3} 0$ projeto partiu, inicialmente, da reunião dos dados cartoriais compilados pelos projetos anteriores de Gwendolyn Middlo Hall sobre a população africana da Louisiana, Afro-Louisiana History and Genealogy (Hall, 2000), e dos dados coletados por Walter Hawthorne em cartórios do Maranhão.

A reunião de dados e fontes digitalizadas oriundos dos múltiplos arquivos que contam a história da experiência dos africanos e seus descendentes em grandes portais da internet abre novos caminhos para a visualização e a interpretação da diáspora africana. Se, antes, os documentos que testemunhavam sua história encontravam-se espalhados por inúmeras instituições, espelhando a própria violência da dispersão, as ferramentas digitais proporcionam análises a partir do sentido inverso dessa história custodial. Em escala sem precedentes, é possível localizar os vínculos entre as pessoas e os destinos de grupos que tinham a mesma origem africana, sem ignorar os efeitos disruptivos do tráfico em milhares de trajetórias.

No entanto, em termos globais, quando analisamos o balanço dos 54 projetos elaborado por Flores (2016), notamos que a maioria das iniciativas enfoca regiões específicas, sobressaindo os estados escravistas do sul dos Estados Unidos, sendo raras aquelas que privilegiam outras territorialidades das Américas. No que toca especificamente ao Brasil, poucos projetos realçam seu passado. As exceções são os dados disponibilizados por Hawthorne sobre o Maranhão e o projeto Slave Societies Digital Archives, coordenado por Jane Landers na Vanderbilt University, que oferece milhares de imagens digitais de documentos referentes às vidas das pessoas escravizadas que viveram no Brasil. ${ }^{4}$ Em linhas gerais, apesar de estarem sediados em diferentes países, há uma predominância absoluta de projetos coordenados por instituições anglófonas do hemisfério Norte.

No volume African Studies in the Digital Age, editado por Barringer e Wallace (2014), essa mesma assimetria entre espaços acadêmicos do Norte e do Sul foi observada na área 
de estudos africanos, tanto no volume dos conteúdos acessíveis às bibliotecas dos países da África quanto, ironicamente, no acesso a conteúdos sobre o continente disponíveis na web. Tais disparidades refletem, em parte, a distribuição desigual da infraestrutura global de comunicação na África subsaariana, segundo Sharath Srinivasan e Claudia Abreu Lopes (2016). As autoras destacam a importância de considerarmos os impactos dessa realidade na vida comunitária e nos projetos de desenvolvimento voltados para os países do continente.

Do ponto de vista epistemológico, o conjunto das desigualdades mencionadas pode potencializar a projeção de imagens globais dos fenômenos contidos nas bases, sem contemplar devidamente a diversidade de realidades históricas marcadas pela escravidão e seu legado, por exemplo, nos mundos de colonização portuguesa, espanhola, holandesa e francesa.

Dessa forma, a base de dados que estamos desenvolvendo sobre as origens e as biografias dos africanos trazidos para Minas Gerais contribui para posicionar o interior da América portuguesa e as dinâmicas do Atlântico Sul junto a outras iniciativas já em curso. 0 município de Mariana concentrava a maior população escravizada da capitania, tornando-se um ângulo privilegiado para a compreensão da diáspora africana no Brasil. ${ }^{5}$ Em síntese, com base no acúmulo de experiências metodológicas que vão desde o projeto Slave Voyages (e seu importante legado) até às iniciativas recentes mais em sintonia com o biographical turn, oferecemos um contraponto a partir do Sul.

\section{DESCRIÇÃO E OBJETIVOS DA BASE DE DADOS}

base de dados que desenvolvemos é constituída por quatro núcleos principais de infor-
mações compulsadas em documentos de natureza cartorial, fiscal, carcerária e inquisitorial. As tipologias produzidas pelos cartórios do primeiro e segundo ofício de Mariana (conservadas no Arquivo Histórico da Casa Setecentista de Mariana [AHCSM]) constituem o segmento mais denso dos registros. Englobam transações comerciais de compra e venda ou formação de sociedades envolvendo a posse de escravizados ou a transmissão de propriedade por meio das últimas vontades em testamento (etapa do trabalho já concluída) ou partilha em inventários post mortem. Em todos esses casos, os africanos e seus descendentes são listados, caracterizados (nome, idade, origem etc.) e avaliados. Os dados oriundos dessas descrições permitem situá-los em um universo mais amplo, por meio da abordagem digital. 0 grau de seriação, no entanto, oscila de uma tipologia para outra, como é o caso dos testamentos, que oferecem informações sobretudo de natureza qualitativa, possibilitando compreender as relações sociais entre os proprietários e os africanos, por exemplo. 
No caso dos documentos da Câmara Municipal de Mariana, temos a descrição de africanos e seus descendentes na documentação da cadeia pública e nos registros das almotaçarias, os quais fornecem a listagem daqueles que tinham vendas, mormente as africanas escravizadas que foram trazidas da região da Costa da Mina. Além disso, dispomos também dos róis das cobranças dos quintos, cujo valor era estabelecido pelo número de escravizados, fornecendo seus respectivos nomes e "nações". ${ }^{6}$

Os dados elaborados pelo Tribunal da Inquisição, por sua vez, são extraídos de denúncias contra lideranças das comunidades africanas (normalmente sacerdotes) ou seus seguidores envolvidos em práticas religiosas consideradas heréticas durante o violento processo histórico de sua associação com o demônio. Parte dessas informações é facilmente seriável, como nome do denunciado, idade, nação e proprietário. Ademais, tais fontes asseguram que o usuário localize os processos e as denúncias disponíveis no site da Torre do Tombo, sustentando, assim, análises sobre suas cosmologias, vínculos sociais e políticos. ${ }^{7}$

No final do segundo semestre de 2019, a base está se aproximando de 10 mil entradas, compiladas principalmente a partir dos documentos cartoriais e inseridas em planilha do programa Google Sheets. 0 planejamento do projeto prevê sua expansão nos próximos anos, para abranger informações de outros arquivos da região mineradora, como os de Ouro Preto, que em parte já foram fotografados pela coordenação desse projeto. E, nos dois casos, prevê sua ampliação para registros paroquiais de batismo, óbito e casamento. A coleta de informações prevista para ser realizada nesses conjuntos seguirá as linhas gerais dos procedimentos adotados em relação às tipologias já descritas. Ou seja, privilegiaremos os dados que permitam reconstituir as trajetórias dos africanos e de seus descendentes.

0 projeto é desenvolvido no âmbito do Departamento de História da Universidade Estadual de Campinas (Unicamp) e, após a conclusão de sua primeira etapa, em 2021, estará disponível gratuitamente no site do Instituto de Filosofia e Ciências Humanas (IFCH). ${ }^{8} \mathrm{O}$ intuito é contribuir para que esse se torne um polo de referência em abordagens digitais no campo da história social, sobretudo no que toca à gestão de bases de dados e preservação digital. Apostamos no desenvolvimento de metodologias de trabalho interdisciplinar e em equipe, como será mais bem detalhado adiante.

Em resumo, os principais objetivos da construção e da disponibilização online da base de dados sobre a população escravizada de Minas Gerais são: 1) conhecer as origens dos africanos e de seus descendentes a partir de suas "nações", tornando possível a localização de novas rotas do tráfico no interior do continente africano com base nessa nomenclatura; 2) oferecer elementos sobre a experiência social de africanas e africanos que viveram na 
região mineradora; 3) ensejar abordagens biográficas por meio do rastreamento de uma mesma pessoa em diversos momentos de suas vidas; 4) possibilitar que cidadãos brasileiros descendentes de africanos possam traçar genealogias de seus ancestrais; e, por fim, 5) construir atlas digitais interativos para serem utilizados em aulas dos Ensinos Fundamental e Médio, contribuindo para a implementação da Lei nº 10.639 (Brasil, 2003), que tornou obrigatório o ensino de história da África e da cultura afro-brasileira.

Por terem sido elaborados com diferentes propósitos, os documentos compulsados pela base permitem observar as trajetórias de vida dos escravizados a partir de múltiplos ângulos. Por exemplo, é possível encontrar uma mesma pessoa sendo descrita no pagamento dos quintos; no testamento do colono português que detinha sua posse; nos livros de alforrias; e nas denúncias da Inquisição, quando podemos compreender seu papel de liderança nas comunidades africanas que se organizavam em torno dos cultos a seus ancestrais. Portanto, os vieses e filtros coloniais plasmados na feitura dos registros variam entre um documento e outro, 0 que facilita também o trabalho de crítica documental e, evidentemente, propicia o cruzamento de informações sobre uma mesma pessoa. Permitem verificar quem são os agentes históricos que têm voz perante os escrivães e suas relações sociais com as pessoas escravizadas que estão sendo descritas ou mencionadas. 0 Quadro 1 resume os principais tipos de documentos compulsados.

Quadro 1 - Tipologias documentais

\begin{tabular}{|l|l|}
\hline \multicolumn{1}{|c|}{ Arquivo } & \multicolumn{1}{c|}{ TIPOLOGIAS } \\
\hline \multirow{2}{*}{ AHCMS } & 1) Testamentos \\
\cline { 2 - 2 } & 2) Inventários \\
\hline & 3) Escrituras 1o e 2o Ofíc \\
\cline { 2 - 2 } & 4) Alforrias \\
\hline & 5) Escrituras (de compra e venda, sociedade, alforrias etc.) \\
\hline \multirow{2}{*}{ AHCMM } & 6) Cobrança de impostos - quintos \\
\hline & 7) Almotaçarias \\
\hline ANTT & 8) Denúncias \\
\hline
\end{tabular}

\section{PROCEDIMENTOS METODOLÓGICOS: ÉTICA E AGÊNCIA HISTÓRICA}

0 s emergentes debates sobre as relações entre ética e dados na produção do conhecimento envolvendo o emprego de tecnologias digitais vêm colocando em perspectiva crítica as dicotomias sujeito/objeto e analógico/digital nos processos de digitalização e de 
elaboração de bases de dados, sobretudo no que tange ao papel social e político de seus coordenadores (Apurro, 2017). O debate ganhou mais urgência nos últimos anos, primeiro, após os escândalos envolvendo as políticas de privacidade e o uso devastador de dados de usuários das empresas gigantes de tecnologia, como o da Cambridge Analytica em 2018, [Não se trata de referência, é apenas o ano do escândalo] e, mais recentemente, com a visibilidade adquirida pelo impacto dos algoritmos do Google na reiteração e no realce de estereótipos de gênero, classe e raça (Noble, 2018). Em ambos os casos, fica evidente que os processos de intermediação entre os usuários e os conteúdos que buscam na internet não são neutros, mas, sim, permeados por algoritmos que expressam interesses comerciais e os vieses constituídos em meio a estruturas de poder desiguais da sociedade contemporânea.

No caso da história digital, o corolário das discussões sobre ética e big data é o de que as bases de dados não são neutras, sobretudo porque o processo de produção das informações históricas que compilamos foi atravessado por uma série de relações sociais no passado. Consequentemente, não estamos apenas desenvolvendo ferramentas de mediação, mas também produzindo significados e, por isso, devemos ser corresponsáveis pelas possibilidades de utilização que se abrem com projetos dessa natureza. Na definição de Tiago Gil (2015: 11), "um banco de dados é quase uma forma de narrativa histórica". Por isso, devem ser sopesadas a construção e a definição de seus campos; que tipo de informação será considerada uma variável e qual sua natureza (codificável e seriável); o que é coletado e o que é deixado nos documentos históricos; e, por fim, devem ser escrutinadas as decisões ligadas à disponibilização da base na internet, como seu sistema de busca e sua interface. ${ }^{9}$

Em termos epistemológicos, outro cuidado prende-se ao fato de que as inúmeras possibilidades de cruzamento de grandes volumes de informações tendem a deslocar o foco das pesquisas para a escala macroanalítica. Esta certamente tem o potencial de desvendar dimensões ainda pouco conhecidas dos fluxos comerciais e lógicas do tráfico e da escravidão, das tendências e características demográficas da população escravizada, entre outros aspectos cruciais, que se tornam mensuráveis apenas em enquadramentos quantitativos e macroanalíticos. Porém, junto com todas essas potencialidades, há o risco de paradigmas centrados em ferramentas analíticas de big data dissiparem a visibilidade das experiências humanas presentes nas entrelinhas das fontes, subestimando a ação histórica e as vozes de sujeitos marginalizados (Williams, 2018).

No limite, a hiperfragmentação das trajetórias de vida por meio da criação de variáveis codificáveis pode configurar uma plataforma de comodificação contemporânea da vida dos africanos, podendo convertê-las em meros produtos acadêmicos a partir de lentes racializadoras. 
Kim Gallon (2016), em seu ensaio "Making a case for the black digital humanities", sublinhou a relevância das tecnologias de recuperação (technology of recovery) no campo das humanidades digitais como parte de estratégias de visibilização da experiência humana de grupos marginalizados por meio de plataformas digitais, sobretudo na área de black studies. Em diálogo com Tara McPherson (2012), Gallon (2016) argumenta ainda que, sem uma apreciação crítica do processo mais amplo em que se inserem, os projetos tendem a reproduzir, no campo das humanidades digitais, estruturas desiguais de poder, entre elas a racialização de minorias.

Para lidar com essas questões, formulamos metodologias que permitem ao usuário enxergar as relações de poder assimétricas plasmadas nos documentos e, concomitantemente, aproximá-lo das vozes e da experiência histórica das populações escravizadas da região de Minas Gerais da forma mais densa possível.

O equacionamento desse desafio metodológico implica o exercício de crítica documental, que começa com uma reflexão sobre as dinâmicas subjacentes à constituição dos arquivos em contexto escravista. As lógicas que informaram a constituição do que hoje compreendemos como fontes primárias são derivadas das relações sociais que buscavam legitimar e reiterar a posse de pessoas. 0 próprio ato de descrever, avaliar e caracterizar as africanas e os africanos era expressão do exercício do poder senhorial e colonial. Os cartórios e todo o aparato burocrático que gerou a documentação arquivística utilizada no projeto tinham por função normalizar a escravização daquelas pessoas. Daí emergiram as informações que se tornam variáveis por meio do tratamento digital. Por exemplo, o nome português atribuído a cada africano pode ser considerado um índice que encapsulava a violência simbólica do domínio escravista. Haviam sido impostos contra suas vontades, sobrepondo-se aos nomes que haviam recebido nos contextos africanos. ${ }^{10}$

Os catálogos dos arquivos reificam as lógicas de organização das informações que eram centradas no protagonismo dos segmentos sociais possuidores de escravizados, pois os documentos são normalmente indexados pelos nomes dos proprietários. Exceções são os livros paroquiais e as fontes sobre as alforrias. Ainda assim, tendencialmente registram os nomes dos proprietários que forneceram as informações sobre os africanos para os escrivães.

Ao mesmo tempo, todas aquelas descrições dispostas nos códices, conforme a ideologia senhorial, trazem dados biográficos importantes sobre a vida dos africanos e de seus descendentes e, por vezes, suas redes familiares e sociais. Por isso, é importante o desenvolvimento de metodologias que permitam sua compilação de forma crítica e, ao mesmo tempo, abrangente.

À luz da problematização realizada por Gallon (2016), já mencionada, adotamos uma inversão estrutural do método de organização e disposição das informações históricas no 
arquivo colonial durante o processo de recolha de seus dados e estabelecimento de sua representação digital. Em vez de criar os registros na base em função do nome do senhor, optamos por abrir um registro novo para cada pessoa escravizada descrita nos documentos. Por exemplo, se encontramos o testamento de um português que listava a posse de cinco pessoas africanas acompanhadas de suas respectivas informações (nome, nação, idade e, por vezes, valor), abrimos cinco novos registros na planilha Google Sheets, um para cada pessoa. Ou seja, o eixo central da organização da base de dados é a singularidade e a agência histórica dos africanos e de seus descendentes. Tal pressuposto é o que orienta a lógica de inserção e recuperação das informações a partir do sistema de busca em linguagem SQL (Structured Query Language). Não se trata de ignorar o nome do senhor ou de deturpar informações históricas. Na verdade, essa variável é preservada em todos os cinco hipotéticos registros. Desse modo, ao mesmo tempo que a relação de poder senhor-escravo continua sendo passível de análise, o usuário poderá rastrear a vida da pessoa escravizada em outros documentos indexados pelo nome do proprietário, flagrando uma mesma pessoa escravizada (ou forra) em uma cadeia maior de informações com a qual estava relacionada. Sem o nome do proprietário, seria difícil realizar com sucesso tal procedimento. Como veremos adiante, essa estratégia que envolve a retenção do nome do proprietário ou do ex-proprietário é importante também para a desambiguação e o despiste de homônimos no sistema de busca.

\section{PADRONIZAÇÃO DAS VARIÁVEIS: COMO PRESERVAR A HISTORICIDADE DAS VOZES AFRICANAS PRESENTES NAS VARIAÇÕES ORTOGRÁFICAS?}

0 segundo desafio a ser enfrentado na abordagem digital em relação a documentos do século XVIII diz respeito à transposição da grafia daquele período para o sistema informatizado de preenchimento dos registros e de recuperação de informações. Naquele contexto, a língua ainda não tinha a relação que passou a ter com o Estado-nação no século XIX, quando foi sendo codificada lexicalmente e subordinada a uma norma ortográfica fixa. No Antigo Regime português, ainda que existissem manuais de caligrafia, a alfabetização, a escolarização e a formação profissional não eram processos regulares. Os escrivães gozavam de relativa liberdade quanto à forma de grafar as palavras, o que resultava em muitas variações. Por exemplo, uma mesma pessoa poderia ter seu nome escrito de múltiplas formas ao longo de sua vida: Joseph, Jozé, Jozeph etc. No tratamento digital, mesmo que a diferença na variação de um termo seja de apenas um caractere, a depender do filtro da busca, cada variação pode ser lida digitalmente como sendo referente a múltiplas pessoas, embora todas se refiram a um mesmo personagem. 
HUMANIDADES DIGITAIS E DIÁSPORA AFRICANA: QUESTÕES ÉTICAS E METODOLÓGICAS NA ELABORAÇÃO DE UMA BASE DE DADOS SOBRE A POPULAÇÃO ESCRAVIZADA DE MARIANA (SÉCULO XVIII)

Esse quadro impõe a necessidade de tomada de decisões sobre os processos de atualização do português arcaico. A adaptação e a fixação das formas setecentistas para uma forma estática contemporânea devem ser precedidas de uma reflexão sobre possíveis perdas das dimensões históricas dos registros, caso sejam inseridos apenas em um campo por meio de uma uniformização unilateral.

Essa discussão torna-se primordial, por exemplo, quando nos deparamos com o descritor de origem dos africanos: "nação". Trata-se de uma nomenclatura cujos usos e sentidos oscilavam intensamente, podendo significar topônimos das macroáreas da organização do tráfico na costa africana; portos de embarque; unidades políticas; identidades que expressavam microfiliações políticas; metaetnônimos ou etnônimos que designavam identidades étnicas mais específicas. Dependendo do momento de sua trajetória e do contexto em que uma pessoa era descrita, a nação poderia oscilar de um subgrupo para o descritor genérico mais amplo criado pelos agentes do tráfico, e vice-versa. Em todos esses casos, a solução encontrada na execução do projeto foi a transcrição da grafia original em um primeiro campo (exatamente como aparece nos documentos) e a abertura de um segundo campo na planilha para padronizar a grafia das nações, possibilitando seu tratamento estatístico por meio de seriação.

A justificativa metodológica para a manutenção das grafias originais da nomenclatura no primeiro campo é sua relevância para a etnolinguística histórica. As nações, tal como foram redigidas pelos escrivães, podem conter o encapsulamento de múltiplas dinâmicas forjadas nas interações entre diversos agentes do tráfico e as narrativas dos próprios africanos sobre suas origens (reinos, designação etnolinguística, linhagem, territorialidade etc.). Nesse último caso, podem designar suas concepções sobre formas de pertencimento com base em ancestralidade e territorialidade. Vários termos claramente refletem pronúncias africanas do léxico que descrevia suas origens. Considerando que eram palavras novas sendo incorporadas ao mundo colonial, os escrivães muitas vezes tendiam a anotá-las conforme ouviam-nas, mas adaptando-as à transcrição fonética portuguesa. Os termos específicos de origem africana apareceriam concomitantemente ou sobrepostos a descritores mais genéricos atribuídos pelos agentes do tráfico, como "Mina" significando Costa da Mina.

Além disso, o historiador Marcos Abreu Leitão Almeida (2012) argumenta que a grafia de várias nações pode conter a transcrição portuguesa da pronúncia dos intérpretes africanos que auxiliavam os escrivães durante os registros. Segundo o autor, as marcas fonéticas das nações podem expressar a predominância demográfica dos grupos sobre quem aqueles que atuavam como línguas tinham maior conhecimento. Eles apresentavam maneiras específicas de nomear suas próprias procedências e a de outros grupos. ${ }^{11}$ 
Com base nessas considerações, buscamos criar condições para que pesquisadores de diversas áreas desenvolvam pesquisas na base de dados que franqueiem a recuperação de fragmentos das narrativas africanas que se encontram silenciadas nos arquivos coloniais.

É possível localizar vários descritores de origem influenciados por perspectivas africanas a respeito de suas procedências na região do golfo do Benim. Por exemplo, é comum em Minas Gerais a ocorrência da nação "Ladano", que provavelmente é a transcrição de Alladahonu (Coissy, 1955). Na área Gbe da África Ocidental, o termo significava "gente da casa de Alada" (Pares, 2017 48), expressando, portanto, a filiação política dos súditos do antigo reino de Aladá, que ficava no sudeste do território onde atualmente é o Benim (Law, 1997). Tal região foi invadida pelo reino do Daomé em 1724 no contexto das guerras de sua expansão política e militar sob a liderança do rei Agadja, resultando na escravização de milhares de pessoas, que acabaram sendo deportadas para o Brasil (Soares, 2007; Silva Jr., 2011; Maia, 2013).

Na documentação que compulsamos, o etnônimo relacionado com Alladahonu emerge como "Ladano" e "Ladana", indicando uma inflexão de gênero adaptada à língua portuguesa. Além disso, oscila também para as formas "de nação Ladá" ou "nação Ladá". Todas essas variações foram mantidas na base de dados no campo "nação", a fim de capturar o processo histórico que mediava sua difusão. Já no campo "nação atualizada", as flutuações foram padronizadas como "Aladá", que é o nome africano da unidade política de onde as pessoas daquele grupo eram oriundas.

Encontramos também uma grande volatilidade quanto ao termo utilizado na documentação para descrever os povos de língua iorubá que foram escravizados e levados para a área mineradora: "Nagô", "Nagó", "Anagô", "Anagu", "Anagonou" e "Nagouno". No caso em apreço, Nagô tornou-se a forma mais comum no Brasil contemporâneo. Possivelmente, as formas originais de suas variações trazem as marcas fonéticas dos falantes de língua do grupo Gbe (sobretudo Fon), predominantes em Minas Gerais (Castro, 2002; Maia, 2013; Lima, 2018). Portanto, as flutuações "Nagono", "Naguno", "Anagono", "Anagô" podem ser evidências da nomenclatura colonial permeável ao modo como os grupos Gbe da baía do Benim descreveriam no cotidiano das vilas mineradoras do século XVIII os grupos iorubás seus vizinhos situados a leste, que estavam presentes nas Minas em menor número.

Seguindo nossa opção metodológica, decidimos nesse caso e nos demais por: 1) manter essas formas originais em um campo ("nação") e, em um segundo campo ("nação padronizado"), 2) estabilizar as variações, considerando os seguintes critérios, na ordem que segue:

a. padronizar as variações da nomenclatura para o termo, conforme formas africanas atuais, quando é possível estabelecê-las; 
HUMANIDADES DIGITAIS E DIÁSPORA AFRICANA: OUESTÕES ÉTICAS E METODOLÓGICAS NA ELABORAÇÃO DE UMA BASE DE DADOS SOBRE A POPULAÇÃO ESCRAVIZADA DE MARIANA (SÉCULO XVIII)

b. fixar, conforme a grafia contemporânea lusófona, quando essas palavras ainda são usadas;

c. ou, não sendo possível as duas opções anteriores, padronizar as oscilações para o termo mais recorrente na documentação.

Em resumo, as facetas da predominância demográfica Gbe podem ser compreendidas pela forma como os descritores de origem aparecem nos documentos. Deixar de inserir na base as grafias originais e sua instabilidade equivaleria a apagar digitalmente as evidências históricas das dinâmicas de interação social referidas. Com efeito, à luz dos estudos sobre as conexões entre África e Brasil, optamos por manter em dois campos a nomenclatura que designava a origem das pessoas escravizadas, repetindo então: no primeiro, a versão original dos documentos em todas as suas variações; e, no segundo campo, a versão fixa atualizada, para que possa ser codificada, de modo a facultar que todo o grupo seja recuperável na busca.

\section{Quadro 2 - Nomenclatura das origens africanas em Mariana}

\begin{tabular}{|l|c|}
\hline \multicolumn{1}{|c|}{ OrIGINAL } & AtualizAdo \\
\hline Ladá, Lada, Ladano, Ladanu, Ladana & Aladá \\
\hline Anagô, Anagó, Anago, Anagonu, Naguno, Nagono & Nagô \\
\hline Fom, Fono, Fona, Fon & Fon \\
\hline Sabarú, Sabará, Sabalu & Savalou \\
\hline Courá, Courano, Courana & Courá \\
\hline
\end{tabular}

Quanto ao nome dos proprietários, optamos por padronizar a grafia já na entrada das informações na base. Assim, aumentaríamos as possibilidades de rastrear os dados sobre os escravizados com mais chances de chegarmos a todas as vezes em que aparecem nos documentos, pois, como vimos, as descrições das pessoas escravizadas sempre fazem referência aos senhores. Abdicar das variações originais dos nomes dos proprietários, nesse caso, não significa perdas relevantes, quando comparadas com as oportunidades de buscas abrangentes que a padronização de seus respectivos nomes possibilita. Em síntese, a padronização viabiliza que a busca recupere informações sobre uma pessoa de forma não fragmentada, conforme cada variação ortográfica dos vocábulos. Por exemplo: 
Quadro 3 - Variação onomástica

\begin{tabular}{|c|c|}
\hline VERSÃO ORIGINAL & VERSÃO PADRONIZADA \\
\hline Joseph, Jozeph, Joze & José \\
\hline
\end{tabular}

As demais variáveis e informações da base foram uniformizadas. Os números por extenso (por exemplo, idade e datas) foram fixados em sua forma numérica. E nos campos formatados para informações qualitativas (não codificáveis) sobre a vida dos escravizados e libertos transcrevemos as informações, adaptando a ortografia para o português contemporâneo.

\title{
AMBIGUIDADE E ESTRATÉGIAS DE DESAMBIGUAÇÃO DE DADOS NAS BUSCAS ONOMÁSTICAS
}

\begin{abstract}
$\triangle$ opção metodológica por abrir um novo registro para cada pessoa escravizada que encontramos nas diferentes tipologias documentais resultou em problemas operacionais que configuram "ambiguidade de dados". Por exemplo, ao realizar buscas pelo nome de uma pessoa escravizada, hipoteticamente Josefa Mina ou simplesmente Josefa, o usuário poderá deparar-se com inúmeros registros, sem ter a garantia de que todos se referem à pessoa pesquisada.

0 problema é agravado por três outros fatores. Primeiro, os nomes portugueses impostos aos africanos em seus batismos não variavam tão significativamente. Segundo, as pessoas escravizadas raramente tinham sobrenome, pois seus primeiros nomes eram acompanhados apenas pelo descritor de suas origens: "nação". A título de exemplo: Maria Angola, Maria de nação Mina, José Mina, João de nação Sabarú. Terceiro, em locais onde havia grande concentração de povos de uma mesma região africana, como era Minas Gerais, a nação auxilia, mas não necessariamente permite, desambiguar de imediato dados sobre as pessoas, porque os descritores de origem tornam-se também comuns. É necessário, então, atrelá-la a outros elementos.
\end{abstract}

Essas ambiguidades nas buscas onomásticas, aqui em análise, são geradas quando as informações sobre os escravizados e libertos passam a ser representadas em células de planilha. No contexto colonial do século XVIII, as características físicas e a inserção de cada pessoa nas relações sociais das freguesias em que viviam poderiam facilmente singularizá-las, de modo que proprietários, capatazes, vizinhos, companheiros de lida e companheiros diferenciavam facilmente uma pessoa da outra. Poucos elementos dessas relações sociais ficaram registrados nos documentos. É preciso estarmos conscientes, portanto, que uma base de dados possibilita a recuperação apenas de fragmentos que caracterizavam uma pessoa naquele universo social mais amplo em que viveram. 
HUMANIDADES DIGITAIS E DIÁSPORA AFRICANA: QUESTÕES ÉTICAS E METODOLÓGICAS NA ELABORAÇÃO DE UMA BASE DE DADOS SOBRE A POPULAÇÃO ESCRAVIZADA DE MARIANA (SÉCULO XVIII)

Apesar de serem fragmentos, eles são absolutamente relevantes para a compreensão daquelas realidades históricas. Acreditamos que o tratamento digital dos fios soltos e rastros deixados por aquelas vivências potencializa as chances de aproximação das nuanças daquele contexto. Mas avançar por esse flanco requer o enfrentamento metodológico dos já enunciados casos de homônimos que abundam nas pesquisas onomásticas em uma base de dados dessa natureza. Embora o problema pudesse emergir em toda a sua extensão no funcionamento do sistema de busca e visualização das informações, é necessário encará-lo e prever soluções já nessa fase da coleta dos dados, porque ela repercutirá nas saídas e nas possibilidades de busca em linguagem SQL.

Como permitir, então, que os usuários possam saber se dois registros ou mais contendo, por exemplo, dados sobre "Maria Mina" referem-se a uma mesma pessoa?

Mais uma vez, é o conhecimento da lógica da produção dos documentos no contexto colonial que nos oferece subsídios para a superação desse desafio técnico. Nossa metodologia para a desambiguação de nomes de pessoas escravizadas utiliza três variáveis. Conforme já foi referido, a descrição dos escravizados obedecia a uma grade comum de informações que diziam respeito à dimensão burocrática da legitimação ideológica da posse de pessoas. 0 dado mais ubíquo que acompanharia as referências aos africanos e crioulos em todas as tipologias seria o nome de seu senhor ou, no caso dos forros, ex-senhor, embora nesse último caso com menos frequência. Portanto, ele é fundamental para o primeiro nível da estratégia de desambiguação.

Outro dado que integrava a gramática básica do processo de comodificação dos escravizados era, como vimos, a menção a suas origens: "nação", a qual estaria sempre associada ao nome que recebiam no batismo. Isso contribui para avançarmos na localização de uma pessoa na base de dados, sobretudo se associada a outras variáveis. No caso dos percursos em que uma pessoa emerge em alguns registros como escravizada e em outros momentos como liberta, havia uma tendência (o que não era regra) de que a nação fosse abandonada e substituída por "preta forra" ou "preto forro" e pela adoção do sobrenome do ex-senhor. Isso ocorria em razão da influência do patronato romano na escravidão ibérica, que previa uma série de obrigações e demonstrações de gratidão e lealdade dos libertos perante seus antigos proprietários. Então, também nesses casos dos libertos, o nome do proprietário e ex-proprietário vai contribuir para rastrearmos a trajetória de vida de uma pessoa na base, possibilitando que localizemos dados sobre suas vidas antes da alforria. Por exemplo, podemos localizá-las nas listas dos impostos ou em escrituras de compra e venda, percebendo por onde transitaram e por qual circuito do tráfico foram trazidas aos arraiais mineiros. 
Ainda que com muito menos frequência, outro elemento ao qual a sociedade colonial escravista de Minas Gerais recorria para diferenciar uma pessoa da outra e, algumas vezes, deixaram-nas registradas nos documentos, eram as marcas corporais. Aparecem nas fontes como cicatrizes decorrentes de episódios violentos e conflitos diversos; sinais de varíola ("sinais de bexiga"); e escarificações rituais que poderiam comumente ser descritas como "sinais de sua nação" ou "sinais de sua terra". Em alguns testamentos, os portugueses chegam a interpretar os sinais no rosto dos africanos ao descreverem suas posses, buscando diferenciar uma pessoa da outra, sobretudo quando tinham o mesmo nome. Em certas freguesias, os escrivães vão desenvolvendo um grau de interesse tão grande pelas escarificações que passam a descrever meticulosamente os cortes na pele, suas formas, texturas e locais do rosto onde estavam inscritas.

Portanto, em razão de sua relevância no contexto setecentista, a estratégia de desambiguação onomástica (ou despiste dos homônimos) está estruturada a partir da recuperação conjunta do a) nome do proprietário, da b) nação e das c) marcas corporais. Isso quer dizer também que todos os resultados de buscas onomásticas (por meio de SQL) trarão, além do nome da pessoa escravizada ou liberta, essas três variáveis, além das referências da fonte da qual foram extraídas. A construção da interface que exibirá os resultados da busca por nome também vai necessariamente evidenciá-las.

Havendo ainda dúvidas ou suspeitas de ambiguidade, o usuário poderá filtrar a busca a partir de dados qualitativos mais específicos, descendo para outros níveis de informações sobre as biografias e as dimensões sociais de suas vidas.

\title{
VISUALIDADE E INTERFACE
}

\begin{abstract}
A lém do funcionamento da busca e de sua interligação com o processo de recolha de dados, a visualização das informações na interface é outra etapa relevante das metodologias interdisciplinares adotadas nos projetos da área de humanidades digitais, em geral, e da história digital, em particular (compreendida aqui como um subcampo das humanidades digitais). Segundo Anne Burdick et al. (2012: 83), no quadro das transformações na materialidade da informação nas tecnologias comunicacionais, "as mídias devem ser vistas como parte do processo de criação de significados". As escolhas tocantes à exibição das informações na tela (ordem em que aparecem, seu design, escolha da fonte, cores, tamanho, disposição na tela e configuração em geral) impactam sobremaneira as formas de produção de conhecimento mediadas pela tecnologia. Por isso, devemos considerar as inter-relações entre forma e conteúdo na história digital, superando uma divisão rígida entre equipes dedicadas somente à materialidade e profissionais dedicados unicamente aos conteúdos.
\end{abstract}


HUMANIDADES DIGITAIS E DIÁSPORA AFRICANA: QUESTÕES ÉTICAS E METODOLÓGICAS NA ELABORAÇÃO DE UMA BASE DE DADOS SOBRE A POPULAÇÃO ESCRAVIZADA DE MARIANA (SÉCULO XVIII)

No caso da base de dados em análise, ao deslocarmos as informações históricas dos aparatos materiais em que se encontram inscritas nos arquivos coloniais e transformá-las em variáveis, criamos inúmeras possibilidades de cruzamentos e combinação de informações em novas escalas de análise. Por outro lado, criamos um obstáculo para que o usuário tenha consciência da integralidade dos documentos dos quais os dados foram compilados e do contexto arquivístico em que se encontram inseridos. A experiência de pesquisa tende a ser marcada pela fragmentação, em virtude de as buscas por variáveis nas bases de dados normalmente serem realizadas por meio de palavras-chave.

Em sua discussão sobre os impactos e meandros dessas transformações, Joshua Sternfeld (2011) enquadrou a problemática a partir de suas conexões entre a arquivística e a história. Propõe que as soluções para a interface devem ser centralizadas na construção e na exibição dos metadados que apontem a localização nos arquivos das informações históricas representadas digitalmente. Essa informação deve ser exposta na interface dos artefatos digitais que lidem com dados históricos de todo tipo. 0 autor argumenta que, na produção do conhecimento historiográfico em contexto digital, tal medida é fundamental para o estabelecimento de uma relação de confiança entre as práticas historiográficas, as instituições e os usuários de sites, bases de dados e aplicativos que trabalham com informações históricas.

Destarte, nossa preocupação converge para a construção de uma base cuja interface do sistema de busca e visualização das informações exiba, independentemente do filtro que 0 usuário venha a adotar, a referência (códice, caixa, prateleira, estante, pasta, lata, livro, fólio etc.) do documento no arquivo e a tipologia documental de que o dado foi extraído. Ou seja, os resultados são mostrados por cada registro de pessoa escravizada. Disso depende não apenas a relação de confiança entre o usuário e a base de dados, mas também a percepção de que os registros foram abertos em função da agência histórica da população africana e de seus descendentes.

No caso de usuários historiadores, haverá a possibilidade de aprofundamento das pesquisas em arquivos a partir da informação localizada na base. Com os documentos originais em mãos, o pesquisador poderá familiarizar-se com a integralidade do suporte material em que o fragmento encontra-se registrado, recuperar informações qualitativas que não foram compiladas na base e conhecer a história custodial da fonte da qual os dados foram extraídos. Ou seja, as bases de dados podem ser artefatos que criam pontes com os arquivos; não necessariamente os substituem.

Em sua última etapa, utilizando ferramentas de georreferenciamento ArcGIS, o projeto pressupõe a elaboração de um atlas interativo das principais localidades de procedência dos 
africanos por meio da representação digital dos descritores de origem ("nação") encontrados na documentação. Isso facultará, por exemplo, que professores de Ensino Médio possam dimensionar visualmente as rotas interioranas do tráfico que ainda são pouco conhecidas e divulgadas em materiais didático-pedagógicos. Por trabalharmos com dados mais permeáveis à autoidentificação e à experiência social dos africanos, é possivel ir além dos pontos de embarque pela visualização dos caminhos que conectavam as regiões de origem aos portos na costa. Tal estratégia contribui para implementação da Lei no 10.639 (Brasil, 2003), que tornou obrigatório o ensino de história da África e da cultura afro-brasileira nas escolas brasileiras. ${ }^{12}$ Os professores terão a opção de explorar esses recursos como material de apoio didático, para historicizar a diversidade das origens africanas, evitando as armadilhas das imagens racializadas, estáticas e generalizadas do continente e de sua história.

\section{HISTÓRIA DIGITAL E ITINERÁRIOS DA FORMAÇÃO DE QUADROS EM NÍVEL DE GRADUAÇÃO}

$A_{\text {a formação de quadros em nível de graduação aptos a lidarem com os recursos digitais }}^{\text {creditamos que as iniciativas na área de humanidades digitais devem preocupar-se com }}$ no campo da história e, ao mesmo tempo, fornecer-lhes subsídios para uma postura crítica no processo de configuração das bases de dados e as implicações de suas escolhas metodológicas. Nesse sentido, o projeto aqui em discussão tem três interfaces principais com práticas didático-pedagógicas.

A leitura das fontes e a alimentação do banco de dados é realizada com uma equipe de alunos de graduação dos cursos da área de humanas da Unicamp que têm interesse em abordagens digitais sobre a história do Brasil colonial e suas conexões com a história da África e da diáspora. ${ }^{13}$

Após a seleção, o trabalho dos bolsistas inicia-se com um treinamento em leitura paleográfica de documentos do século XVIII que foram digitalizados, familiarização com as tipologias documentais e suas variações. Em seguida, passam a ter contato com a lógica dos registros da base, seus campos e o processo de extração e inserção das informaç̃̃es que são consideradas variáveis conforme eixo organizador do projeto. Toda essa etapa é compreendida como um processo de produção de conhecimento interdisciplinar, e ela se aprofunda ao ser entrelaçada com a segunda frente do trabalho de formação de quadros. Esta diz respeito ao envolvimento concomitante dos bolsistas com o grupo de estudos "A diáspora africana no interior do Brasil colonial". Seu principal objetivo é franquear aportes para que os alunos compreendam o contexto em que os documentos foram produzidos, suas potencialidades e 0 
papel da base de dados para avanços na produção de conhecimento sobre a presença africana na formação histórica do Brasil. A participação no grupo é institucionalizada por matrícula em Estudos Dirigidos e oferece dois créditos por semestre, o qual é aberto a todos os alunos de graduação da Unicamp; portanto, não é exclusiva dos bolsistas do projeto.

A partir desses subsídios, os alunos têm a oportunidade de se engajarem em projetos de iniciação científica, formulando problemas de pesquisa com base no contato com a bibliografia, fontes, metodologias de história digital, e, assim, prepararem-se para seguir a carreira acadêmica em nível de pós-graduação.

Por meio das estratégias descritas, buscamos formar profissionais hábeis para o trabalho crítico e interdisciplinar com as ferramentas digitais, desenvolvendo habilidades e, ao mesmo tempo, uma perspectiva ética a respeito das questões subjacentes à história digital, abordando suas implicações epistemológicas, políticas e sociais.

\section{CONSIDERAÇÕES FINAIS}

$\mathrm{O}^{\text {品 }}$ projeto analisado como um estudo de caso ao longo deste artigo engaja-se no esforço de superação de uma imagem genérica e racializada do continente africano e de sua história. Por muito tempo, as milhares de pessoas que foram escravizadas e trazidas para o Brasil entravam nos livros didáticos e na memória coletiva apenas nos capítulos sobre o tráfico e a escravidão. Mais do que escravos e descendentes de escravos, são pessoas escravizadas e descendentes de pessoas escravizadas e, no contexto da escravização na África e de suas vivências nas Américas, encontravam-se inseridas em múltiplas dinâmicas sociais e políticas. Assim, uma abordagem digital de suas origens, à luz da história da África e da diáspora, contribui para um esforço mais amplo de aproximação das complexidades e nuanças da história do continente.

As opções metodológicas da iniciativa levaram em conta também o fato de o projeto ser desenvolvido no país que foi o maior importador de pessoas escravizadas das Américas (mais de 5 milhões de pessoas de um total de cerca de 12 milhões), ${ }^{14}$ o que marcou profundamente sua formação histórica, com consequências na constituição de desigualdades sociais e étnico-raciais. Se um dos principais objetivos do trabalho é expandir o conhecimento sobre as origens das africanas e dos africanos, consequentemente lidamos com a luta por cidadania da população afrodescendente no que toca aos avanços nos estudos sobre a história do país a partir de suas conexões com a África. Propiciar e incentivar a produção de conhecimento histórico nessa área tornam-se, assim, uma potente estratégia de combate aos impactos do racismo estrutural e de seus efeitos no campo epistemológico. 
Ao disponibilizar na internet informações de natureza genealógica e biográfica, o projeto oferece elementos para processos de reparação por meio da promoção do direito à memória, elaboração de identidade e pertencimento da população descendente de africanos. Tais fatores, de natureza ética, social e política, foram considerados nas metodologias que informam a configuração da base e seu funcionamento em ambiente virtual.

A abordagem crítica aqui desenvolvida torna-se possível por entendermos que o percurso que envolve a construção da base de dados é também um processo de produção de conhecimento, indo muito além de uma operação técnica com recursos digitais. Assumir essa dimensão possibilita a superação da dicotomia entre o campo das "humanidades tradicionais" e o das "humanidades digitais", conforme crítica contundente formulada pelos autores de "The dark side of the digital humanities" (Chun et al., 2016) — como se a primeira se ocupasse de "fazer coisas", e a segunda, de "criticar coisas". Na verdade, acreditamos que essa é uma falsa dicotomia, pois qualquer desenvolvimento de projetos na área de história digital deve incluir o trabalho crítico do coordenador e de sua equipe, do início ao fim, demandando a mobilização de conhecimento historiográfico aprofundado sobre o contexto a que a base refere-se e uma ponderação sobre as metodologias a serem adotadas à luz da produção recente sobre o campo. Portanto, argumentamos que o processo de concepção e execução dos projetos em história digital deve ser encarado como uma instância de produção de conhecimento historiográfico dentro das humanidades digitais.

\section{NOTAS}

1 Sou grato às leituras críticas dos três pareceristas anônimos que avaliaram o artigo e também aos comentários e sugestões de Ivana Stolze, lara Schiavinatto, Natã Freitas e Diego Pereira.

2 No site Slave Voyages, além da base de dados, há múltiplos ensaios que comentam e analisam o processo de construção da base de dados e uma infinidade de recursos didático-pedagógicos. Disponível em: <https:// www.slavevoyages.org/>. Acesso em: 8 jun. 2019.

3 Disponível em: <http://enslaved.org/about/>. Acesso em: 8 jun. 2019.

4 SLAVE SOCIETIES. Disponível em: <https://www.slavesocieties.org/>. Acesso em: 10 jun. 2019. 0 projeto inclui em sua equipe Mariza Soares e outros pesquisadores brasileiros.

5 Em 1735, segundo o ouvidor Caetano da Costa Matoso, Mariana tinha 26.892 escravizados; era seguida pelo termo de Sabará, com 24.284; Vila Rica, com 20.863; Rio das Mortes, com 14.400; e Serro Frio, com 10.102. Cf. CODICE Costa Matoso. Edição de Luciano Figueiredo e Maria Veronica Campos. Belo Horizonte: Fundação João Pinheiro/Centro de Estudos Históricos e Culturais, 1999. p. 407.

60 termo "nação", no contexto do tráfico e da escravidão do século XVIII, não deve ser confundido com os conceitos de Estado-nação ou nacionalidade forjados no século XIX. Como será mais bem discutido adiante, 
HUMANIDADES DIGITAIS E DIÁSPORA AFRICANA: QUESTÕES ÉTICAS E METODOLÓGICAS NA ELABORAÇÃO DE UMA BASE DE DADOS SOBRE A POPULAÇÃO ESCRAVIZADA DE MARIANA (SÉCULO XVIII)

"nação" designa uma variada nomenclatura relacionada com as origens africanas. Podem significar tanto grupos étnicos e identidades políticas quanto noções territoriais genéricas ligadas à geografia do tráfico.

7 ARQUIVO NACIONAL DA TORRE DO TOMBO. Tribunal do Santo Ofício. Diponível em: <https://digitarq. arquivos.pt/details?id=2299703 >. Acesso em: 23 nov. 2019.

8 Disponível em: <https://www.ifch.unicamp.br/ifch/pesquisa/bases>. Acesso em: 15 dez. 2019. 0 trabalho conta com financiamento da Coordenação de Aperfeiçoamento de Pessoal de Nível Superior (Capes) por meio do projeto "Os grupos étnicos africanos no Brasil colonial: rotas do tráfico e etnicidades (Minas Gerais, século XVIII)", AUXPE 0382/2016 (Grande Prêmio Capes de Teses/Humanidades, 2013). Os bolsistas que trabalham na base são remunerados pelo Programa de Bolsas de Auxílio Social/Unicamp.

9 Esses aspectos serão retomados adiante nas seções sobre metodologia. Para uma perspectiva contemporânea (e mais otimista) sobre aspectos teóricos e metodológicos envolvendo os usos de inteligência artificial na produção historiográfica, consultar Nicodemo e Cardoso (2019: 17-52).

10 Diferentemente do que acontece nos acervos de Minas colonial, documentos referentes a embarcações do século XIX apreendidas no Atlântico podem conter os nomes africanos das pessoas a bordo. As possibilidades metodológicas de uso dessas informações históricas por meio de banco de dados podem ser verificadas em Anderson et al. (2013: 165-191). Para uma análise recente da experiência de pesquisa nos arquivos do tráfico ilegal, ver Miki (2019: 87-105).

11 Almeida (2012). Sobre as possibilidades de identificação dos contextos de origem dos traficados a partir de uma metodologia quantitativa, consultar Bukas-Yakabuul e Silva (2016: 34-43).

12 Essa lei foi ampliada em 2008, quando tornou obrigatório também o ensino de história indígena: Lei nº 11.645 (Brasil, 2008).

13 Atualmente, a equipe de bolsistas do programa Bolsa de Apoio Social (BAS)/Unicamp é formada pelos graduandos Caroline Cunha (história) e Natã Freitas (história). Desde 2016, já fizeram parte da equipe: Jefferson Athaydes (história), Pedro Gericó (história - bolsista IC Faepex), Leonardo Leoz (ciências sociais), Franceline Galdino (letras) e Victor Sampaio (ciências sociais). Além desses, William Carvalho desenvolveu um projeto para a preservação digital dessa base e de outras que compõem o Centro de Pesquisa em História Social da Cultura (Cecult), o que resultou em sua monografia de bacharelado e em seu projeto de mestrado em ciências da informação na Universidade de São Paulo (USP) (Silva, 2018). A equipe de informática do IFCH da Unicamp que auxilia no projeto é coordenada por Eduardo Rigato.

14 Durante toda a era do tráfico transatlântico, o Brasil era o destino, sozinho, de cerca de 5,8 milhões de pessoas do total de cerca de 12,5 milhões de africanos deportados da África. Cf. Eltis e Richardson (2010).

\section{REFERÊNCIAS BIBLIOGRÁFICAS}

ALMEIDA, M. A. L. de. Ladinos e boçais: o regime de línguas do contrabando de africanos (1831-c. 1850). 2012. Dissertação (Mestrado em História), Universidade Estadual de Campinas, Campinas, 2012.

ANDERSON, R.; BORUCKI, A.; SILVA, D. D. da; ELTIS, D.; LACHANCE, P.; MISEVICH, P.; OJO, O. Using African names to identify the origins of captives in the transatlantic slave trade: crowd-sourcing and the registers of liberated Africans, 1808-1862. History in Africa, v. 40, n. 1, p. 165-191, 2013. 
APURRO, R. Digitization as an ethical challenge. Al \& Society, v. 32, n. 2, p. 277-283, 2017.

BARRINGER, T.; WALLACE, M. (Org.). African studies in the digital age: disconnects?. Leiden/Boston: Brill, 2014.

BRASIL. Lei no 10.639, de 9 de janeiro de 2003. Disponível em: <http://www.planalto.gov.br/ccivil_03/ Leis/2003/L10.639.htm>. Acesso em: 10 jul. 2009.

BRASIL. Lei no 11.645, de 10 de março de 2008. Disponível em: <http://www.planalto.gov.br/ccivil_03/_ Ato2007-2010/2008/Lei/L11645.htm>. Acesso em: 10 ago. 2019.

BUKAS-YAKABUUL, B.; SILVA, D. B. D. da. From beyond the Kwango: tracing the linguistic origins of slaves leaving Angola, 1811-1848. Almanack, Guarulhos, n. 12, p. 34-43, 2016. Disponivel em: <http://www.scielo.br/scielo. php?script=sci_arttext\&pid=\$2236-46332016000100034\&lng=en\&nrm=iso >. Acesso em: 28 ago. 2019.

BURDICK, A. et al. A short guide to the digital humanities. Cambridge/Londres: MIT Press, 2012.

CÂMARA, S.; BENÍCIO, M. História digital: entre as promessas e armadilhas da sociedade informacional. Revista Observatório, v. 3, n. 5, p. 38-56, 2017.

CASTRO, Y. P. de. A língua mina-jeje no Brasil: um falar africano em Ouro Preto do século XVIII. Belo Horizonte: Fundação João Pinheiro/Secretaria da Cultura do Estado de Minas Gerais, 2002.

CHUN, W. H. K.; GRUSIN, R.; JAGODA, P.; RALEY, R. The dark side of the digital humanities. In: GOLD, M.; KLEIN, L. (Org.). Debates in the digital humanities. Minneapolis: University of Minnesota Press, 2016. Disponível em: <https://dhdebates.gc.cuny.edu/read/untitled/section/ca35736b-0020-4ac6-9ce7-88c6e9ff1 bba>. Acesso em: 15 dez. 2019.

COISSY, A. L'arrivee des "Alladahonou" a Houawe. Études Dahoméennes, n. 13, p. 33-34, 1955.

ELTIS, D.; BEHRENDT, S.; RICHARDSON, D.; KLEIN, H. (Ed.). The trans-atlantic slave trade: a database on CD-ROM. Cambridge, UK: Cambridge University Press, 1999.

; RICHARDSON, D. Atlas of the transatlantic slave trade. New Haven: Yale University Press, 2010.

FLORES, J. Digital resources for the study of global slavery and slave trade. 2016. Disponivel em: <https:/l networks.h-net.org/node/11465/pages/143424/digital-resources-study-global-slavery-and-slave-trade>. Acesso em: 14 maio 2018.

GALLON, K. Making a case for the black digital humanities. In: GOLD, M.; KLEIN, L. (Org.). Debates in the digital humanities. Minneapolis: University of Minnesota Press, 2016. Disponivel em: <https://dhdebates.gc.cuny. edu/read/65be1a40-6473-4d9e-ba75-6380e5a72138/section/fa10e2e1-0c3d-4519-a958-d823aac989eb\#en39r>. Acesso em: 13 abr. 2017.

GIL, T. Como se faz um banco de dados (em história). Porto Alegre: Ladeira Livros, 2015.

HALL, G. M. (Org.). Afro-Louisiana history and genealogy, 1699-1860. (CD-ROM). Baton Rouge: Louisiana State University Press, 2000. Disponível em: <https://www.ibiblio.org/laslave/>. Acesso em: 15 dez. 2019.

LAW, R. The kingdom of Allada. Leiden: Research School CNWS, School of Asian, African, and Amerindian Studies, 1997.

LIMA, I. S. A voz e a cruz de Rita: africanas e comunicação na ordem escravista. Revista Brasileira de História, São Paulo, v. 38, n. 79, p. 41-63, dez. 2018. 
HUMANIDADES DIGITAIS E DIÁSPORA AFRICANA: QUESTÕES ÉTICAS E METODOLÓGICAS NA ELABORAÇÃO DE UMA BASE DE DADOS SOBRE A POPULAÇÃO ESCRAVIZADA DE MARIANA (SÉCULO XVIII)

LUCCHESI, A. Por um debate sobre história e historiografia digital. Boletim Historiar, Sergipe, n. 2, p. 45-57, mar./abr. 2014.

MAIA, M. De reino traficante a povo traficado: a diáspora dos courás do Golfo do Benim para as minas de ouro da América Portuguesa (1715-1760). 2013. Tese (Doutorado em História), Universidade Federal do Rio de Janeiro, Rio de Janeiro, 2013.

MARQUES, L. Digital history of the transatlantic slave trade: an interview with David Eltis. Tempo, Niterói, v. 25, n. 2, p. 520-527, 2019. Disponivel em: <http://www.scielo.br/scielo.php?script=sci_arttext\&pi$d=\$ 1413-77042019000200520 \& \mid n g=e n \& n r m=i s o>$. Acesso em: 25 jul. 2019.

MCPHERSON, T. Why are the digital humanities so white? Or thinking the histories of race and computation. Debates in the Digital Humanities, University of Minnesota Press, p. 139-160, 2012. Disponível em: $<$ https://minnesota.universitypressscholarship.com/view/10.5749/minnesota/9780816677948.001.0001/ upso-9780816677948-chapter-17>. Acesso em: 20 maio 2015.

MIKI, Y. In the trail of the ship. Social Text, v. 37, n. 1, p. 87-105, 2019.

MILLER, J. C. A historical appreciation of the biographical turn. In: LINDSAY, L.; SWEET, J. W. (Org.). Biography and the Black Atlantic. Filadélfia: University of Pennsylvania Press, 2013. p. 19-47.

NICODEMO, T. L.; CARDOSO, O. P. Metahistory for robots: knowledge in the artificial intelligence era. História da Historiografia, v. 12, n. 29, p. 17-52, jan./abr. 2019.

NOBLE, S. U. Algorithms of oppression: how search engines reinforce racism. Nova York: New York University Press, 2018.

PAES, M. L. Arquivo: teoria e prática. Rio de Janeiro: FGV, 2004.

PARES, N. O pai, o rei e a morte: a religião vodum na antiga Costa dos Escravos na África Ocidental. São Paulo: Companhia das Letras, 2017.

SILVA, W. de C. A construção e a preservação de bases de dados digitais para a pesquisa histórica: um estudo de caso no Centro de Pesquisa em História Social da Cultura - Cecult. 2018. Monografia (Bacharelado em História). Universidade Estadual de Campinas, Campinas, 2018.

SILVA JR., C. Identidades afro-atlânticas: Salvador, século XVIII (1700-1750). 2011. Dissertação (Mestrado em História), Universidade Federal da Bahia, Salvador, 2011.

SOARES, M. Rotas atlânticas da diáspora africana: da baía do Benim ao Rio de Janeiro. Niterói: UFF, 2007.

SRINIVASAN, S.; LOPES, C. Africa's voices versus big data? The value of citizen engagement through interactive radio. In: HEMER, O.; TUFTE, T. (Org.). Voice \& matter. communication, development and the cultural return. Bohus: Nordicom, 2016. p. 155-172.

STERNFELD, J. Archival theory and digital historiography: selection, search, and metadata as archival processes for assessing historical contextualization. The American Archivist, v. 2, n. 74, p. 544-575, 2011. Disponível em: <http://www.jstor.org/stable/23079050>. Acesso em: 13 abr. 2019.

WILLIAMS, D. Digital approaches to the history of the atlantic slave trade. Oxford research encyclopedia of African history. 20 nov. 2018. Disponivel em: <https://oxfordre.com/africanhistory/view/10.1093/acrefore/9780190277734.001.0001/acrefore-9780190277734-e-121>. Acesso em: 29 jun. 2019. 